\title{
Helen Salisbury: Measuring continuity of care
}

\author{
Helen Salisbury GP \\ Oxford
}

"My biggest problem is that thanks to NHS cuts it is impossible to see the same GP twice-unless I want to wait weeks-and it is so humiliating to explain my history to yet another relative stranger." This sentiment was expressed by a patient on Twitter recently, and it's likely that others share this feeling.

Continuity matters to patients, and it matters to doctors too. When discussing the appeal of a career in general practice with newly qualified doctors, continuity of care is a key factor. GPs see their patients for minor illnesses and major ones, for antenatal care, and with their children. We look after several generations of the same family, and our role covers new baby checks to end-of-life care. This doesn't just provide the informational continuity that all GPs should have, where you have the right notes in front of you, but also relational continuity when you know the patient.

However, this traditional long term relationship is being eroded. In some areas, waiting times are so long for anything other than an emergency that patients have little choice but to take the next appointment with whoever is available. ${ }^{1}$ This is partly related to understaffing, but it's undeniably also a result of prioritising access over continuity. Cash has been injected into general practice to provide appointments at evenings and weekends. These have mostly shuffled existing doctors around to work elsewhere on a Sunday afternoon rather than in their own practice during working hours. $^{2}$

Access is politically important, and GP waiting times are a highly sensitive issue. They're also easy to measure: at any given moment, when is the next available appointment? And when something is measured it can be incentivised. The Quality and Outcomes Framework, introduced in 2004, works by rewarding coded processes and activities. We learnt quickly that, if you financially incentivise an activity, it's likely to happen, as we're all looking endlessly for ways to keep our practices viable. The unfortunate flipside is that attention may be diverted from equally important domains or activities that aren't financially rewarding.

So, if continuity is important-and lots of evidence shows that it improves patient satisfaction, reduces unnecessary referrals and admissions, and even increases longevity ${ }^{3}$ - should we be making greater efforts to measure it? Tools do exist, ${ }^{4}$ and it shouldn't be difficult to make them generally applicable. Once we have a measure, we can assess the impact on continuity from any proposed changes to our working practice.

If we do measure continuity, should we then reward it? Unfortunately, without careful planning, this could turn into yet another stick with which to beat the practices struggling most, which are currently scraping by with too few permanent doctors and a patchwork of locums.

\section{Competing interests: See www.bmj.com/about-bmj/freelance-contributors.} Provenance and peer review: Commissioned; not externally peer reviewed. Patient on Twitter quoted with permission.

1 Gault B. Average GP waiting times exceed two weeks for first time ever. Pulse 2019 Aug 12. http://www.pulsetoday.co.uk/home/finance-and-practice-life-news/average-gp-waitingtimes-exceed-two-weeks-for-first-time-ever/20039156.article. (Login needed.)

2 NHS England. Improving access to general practice. https://www.england.nhs.uk/gp/gpfv/ redesign/improving-access/.

3 Pereira Gray DJ, Sidaway-Lee K, White E, Thorne A, Evans PH. Continuity of care with doctors-a matter of life and death? A systematic review of continuity of care and mortality 10.1136/bmjopen-2017-021161. BMJ Open 2018;8:e021161. 10.1136/bmjopen-2017-021161 29959146

4 Sidaway-Lee K, Gray DP, Evans P. A method for measuring continuity of care in day-to-day general practice: a quantitative analysis of appointment data. $\mathrm{Br} J$ Gen Pract 2019;69:e356-62. 10.3399/bjgp19X701813 30803982

Published by the BMJ Publishing Group Limited. For permission to use (where not already granted under a licence) please go to http://group.bmj.com/group/rights-licensing/ permissions 